World Maritime University

The Maritime Commons: Digital Repository of the World Maritime

University

Reports

Library

2020

\title{
Seafarers' experiences during the COVID-19 pandemic
}

B. Pauksztat

M. Grech

M. Kitada

R.B. Jensen

Follow this and additional works at: https://commons.wmu.se/lib_reports

\section{Recommended Citation}

Pauksztat, B., Grech, M., Kitada, M., and Jensen, R. B. (2020). Seafarers' experiences during the COVID-19 pandemic: Report. doi: http://dx.doi.org/10.21677/wmu20201213

This Open Access Report is brought to you courtesy of Maritime Commons. Open Access items may be downloaded for non-commercial, fair use academic purposes. No items may be hosted on another server or web site without express written permission from the World Maritime University. For more information, please contact library@wmu.se. 

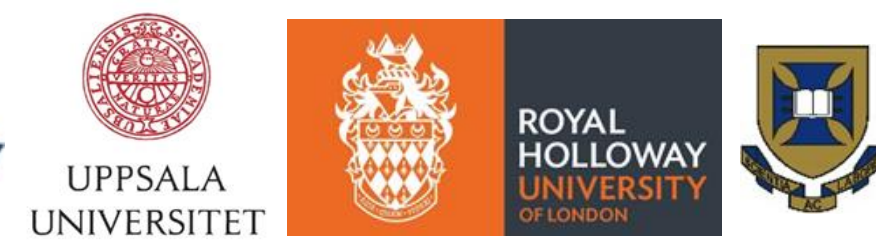

THE UNIVERSITY OF QUEENSLAND

\section{Seafarers' experiences during the COVID-19 pandemic}

\section{Report}

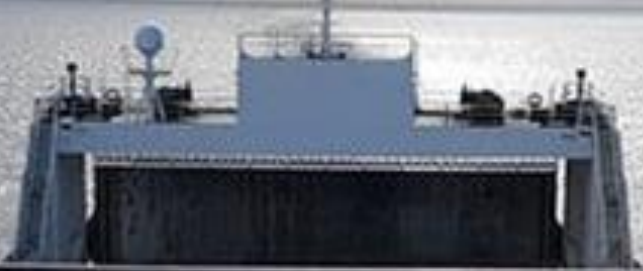




\section{Acknowledgements}

We would like to thank the individuals and organisations who helped with distributing the survey. In particular, we thank the Australian Maritime

Safety Authority for the support provided throughout this study.

Most of all:

A special thanks to the seafarers who participated in the survey.

Authors: Birgit Pauksztat, Michelle Grech, Momoko Kitada and Rikke Bjerg Jensen

Corresponding author: Birgit Pauksztat, e-mail: birgit.pauksztat@fek.uu.se

December 2020

Please cite this report as: Pauksztat, B., Grech, M., Kitada, M., and Jensen, R. B. (2020).

Seafarers' experiences during the COVID-19 pandemic: Report. doi:

http://dx.doi.org/10.21677/wmu20201213

Cover photo by Pixabay via Pexels. 


\section{Executive summary}

This report provides an overview of preliminary findings of a study on the experiences of seafarers during the COVID-19 pandemic. The purpose was to examine the impact of the pandemic on seafarers' work and life on board as well as on their mental health and exhaustion, and identify factors that may mitigate the negative impact of the pandemic.

Data were collected through an online survey between 3 July and 25 September 2020 . The analyses in this report are based on responses from 671 seafarers who were on board when they completed the survey. Respondents had been on board between less than a month and 18 months when they completed the survey (mean: 4 months). 72.5 per cent of respondents were officers, with almost half of the respondents engaged on Northern European flagged vessels. Most had at least limited free Internet access on board. Hence, in interpreting the findings of this study, it is important to note that the data are not based on a representative sample, and they might present a more positive situation than one might obtain from a more representative sample.

Some of the key findings are summarised below:

- The majority of respondents reported serious impacts of the pandemic on crew changes and ship-shore interactions. Respondents' experiences varied with regard to the extent to which the pandemic had affected their employment, non-work life on board and access to supplies.

- Almost half of the respondents reported an increase in workload in comparison to their workload prior to the pandemic.

- On average respondents felt less safe in port than at sea.

- The main difficulties and challenges reported by survey respondents concerned crew changes, ship-shore interactions (incl. lack of shore leave and difficulties in getting supplies), the situation on board (e.g., high workload, fatigue, conflicts, tensions), and lack of information and support from the shipping company.

- There was a 50/50 split in responses between those who reported receiving "a lot" and "enough" support and those who did not. Main sources of support identified by respondents' were shipping companies, family and friends at home and social media.

- Over 40 per cent of the respondents indicated that they had experienced symptoms of depression several times, almost every day or every day during the past seven days, whereas over half reported symptoms of anxiety. Moreover, on average, respondents had experienced symptoms of exhaustion between "once" and "several times" during the past seven days. Feeling exhausted, tired and having sleeping problems were most common, and were experienced by over half of the respondents "several times" or more frequently during the past seven days.

The findings draw attention to several areas of support which different maritime stakeholders can offer to seafarers during the COVID-19 pandemic.

Recommendations for shipping companies:

- Implement effective protective measures and ensure the provision of medical care

- Ensure that viable repatriation plans are in place

- Provide free, fast and reliable Internet on board for seafarers' personal use

- Ensure that seafarers have access to essential supplies and support when needed, including medical care, mental health support, essential goods, as well as possibilities for shore leave

- Ensure a fatigue risk management system is in place 
Governments need to work together to:

- Recognise seafarers as key workers to facilitate crew changes, allow shore leave and provide access to shore-based services.

- Ensure vessels' continued compliance with international laws and regulations, such as the Maritime Labour Convention (MLC, 2006) and Safety of Life at Sea Convention (SOLAS)

- Continue consultation and co-operation between social partners. Under exceptional circumstances, consideration for exempting aspects of MLC, 2006 provisions should include consultation with seafarers or their representatives to ensure all safe options are considered. 


\section{Contents}

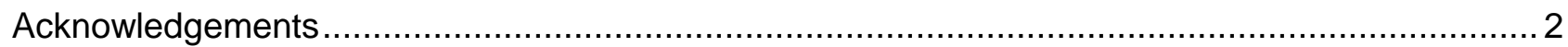

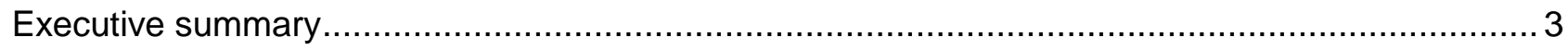

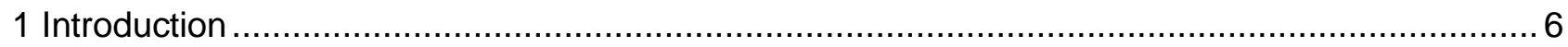

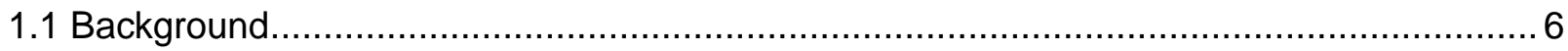

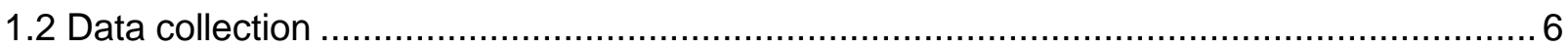

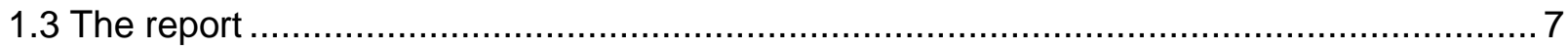

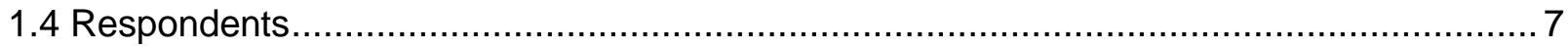

1.5 Overview of key variables included in the study .......................................................

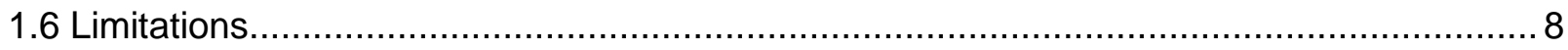

2 Perceived effects of the COVID-19 pandemic .................................................................. 9

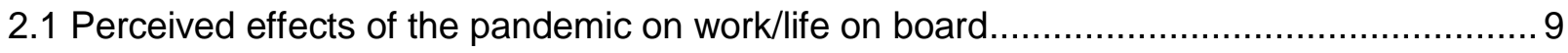

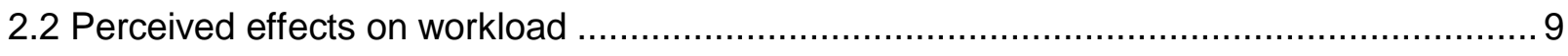

2.3 Perceived effects on personal safety ................................................................. 10

2.4 Perceived difficulties and challenges....................................................................... 10

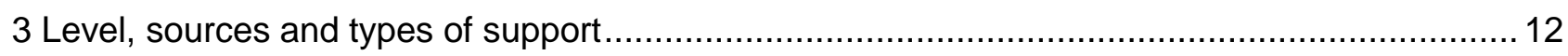

3.1 Perceived level of support and sources of support ................................................... 12

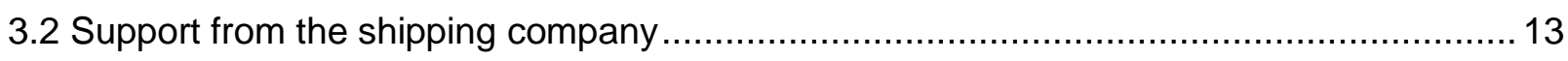

3.3 Communication with family and friends at home ................................................. 15

3.4 Perceived social support from fellow crew members ................................................ 15

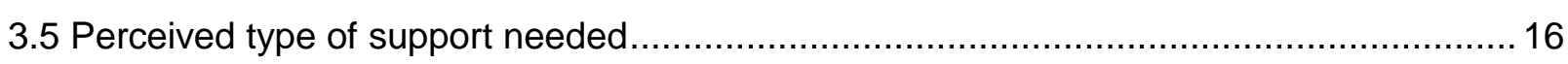

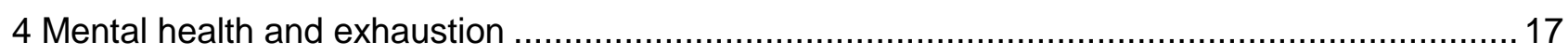

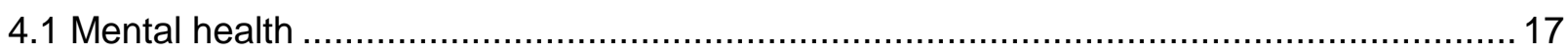

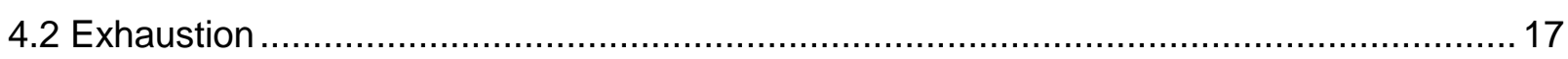

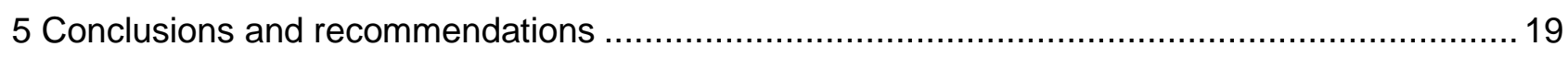

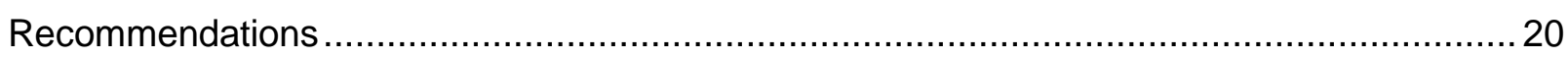




\section{Introduction}

\subsection{Background}

The COVID-19 pandemic has significantly affected people around the world. The World Health Organization (WHO) reported that as of 14 November 2020, there are over 53 million confirmed cases of COVID-19, including over 1.3 million deaths globally. ${ }^{1}$ Many countries have imposed severe restrictions on social gatherings, travel, border crossings, schools, shopping and other activities in order to limit infections. As a result, industries have been significantly affected with some goods and services seeing a rise in demand (e.g. medical equipment, Internet and online conferencing tools), while others are faced with a decline in demand (e.g. hospitality and tourism sectors). The maritime sector is no exception, with, for example, the number of calls at EU ports declining by 13 per cent in the first 45 weeks of 2020 compared to the same period in the previous year. ${ }^{2}$

As many countries are facing challenges to secure their supply chains, the importance of shipping has become increasingly apparent. According to the United Nations Conference on Trade and Development (UNCTAD), ${ }^{3}$ the total world fleet in early 2020 stood at 98,140 ships of 100 gross tons and above. Seafarers' contributions are vital in supporting the continued operation of these ships and, hence, critical supply chains. In 2015, it was estimated that there were about 1.6 million seafarers worldwide. ${ }^{4}$ Each month, approximately 150,000 crew changes need to take place in order for seafarers to be repatriated and to ensure compliance with international maritime regulations and ensure safety, health and welfare of the crew. ${ }^{5}$ During the COVID-19 pandemic, the repatriation of seafarers has faced unprecedented challenges, leaving many seafarers unable to travel to or from their ship.

There is currently little knowledge about the level of support available to seafarers and the challenges they face while they are on board. We therefore designed this study to shed light on and to better understand how the COVID-19 pandemic is affecting seafarers worldwide and to identify factors that may help crews in the future. This project is a collaboration between researchers from Uppsala University (Sweden), World Maritime University (Sweden), University of Queensland (Australia) and Royal Holloway University of London (UK).

\subsection{Data collection}

Data were collected through an online survey between 3 July and 25 September 2020. Seafarers onboard international commercial vessels were invited to participate in the survey, with a shorter follow-up survey conducted about two weeks later. The survey was updated at the end of July, when a few additional questions were included in light of answers to the open questions in the initial survey. The surveys were anonymous.

\footnotetext{
1 https://covid19.who.int/
}

2 EMSA. (2020). COVID-19 - Impact on Shipping Report, 13 November 2020. http://www.emsa.europa.eu/newsroom/covid19-impact/download/6306/4055/23.html

3 UNCTAD. (2020). Review of Maritime Transport 2020.

${ }^{4}$ BIMCO \& ICS (2016). Manpower Report: The global supply and demand for seafarers in 2015. London: Maritime International Secretariat Services Ltd.

5 UNCTAD. (2020). Review of Maritime Transport 2020, 49 
The survey was promoted through national and international seafarer unions and other organisations, such as the International Federation of Shipmasters' Associations (IFSMA); alumni websites and newsletters of the World Maritime University (WMU) and other seafarer training colleges; shipping companies in Denmark, Sweden, Norway, Germany, the Netherlands and the UK, as well as national and international industry organisations and associations, such as the International Maritime Employers' Council (IMEC) and InterManager; the website and Facebook page of the Australian Maritime Safety Authority (AMSA); welfare organisations such as the International Seafarers' Welfare and Assistance Network (ISWAN), Human Rights at Sea, the International Christian Maritime Association (ICMA) and its national associations, and, as far as the local situation permitted, seafarer centres, port chaplains and International Transport Workers' Federation (ITF) inspectors in ports around the world.

\subsection{The report}

In total, 728 responses were received from seafarers who stated that they were currently on board. For the analyses presented in this report, the focus is on the responses to the first survey. Excluding responses to the follow-up survey and responses with a large number of missing answers, left 671 responses for the analyses.

This report provides an overview of the initial results from the survey. Unless stated otherwise, percentages are calculated based on the total of 671 responses. For questions that were added at the end of July, percentages are calculated based on a total of 535 responses. Percentages may not add up to 100 in cases where some respondents did not answer a particular question.

\subsection{Respondents}

Respondents comprised 626 men (93.3 per cent) and 34 women (5.1 per cent), between the ages of 19 and 65 years (mean $=40.2, S D=10.3$ ). Nationalities varied, with most (32.0 per cent) hailing from the Philippines, followed by Sweden (7.7 per cent), Denmark, Germany (7.3 per cent each), Ukraine (5.5 per cent) and India (3.3 per cent). Respondents had worked an average of 17.7 years at sea $(S D=15.5$; range: 0 to 47 years). Most of the respondents ( 75.2 per cent) were officers; 61.5 per cent formed part of the deck crew and 27.8 per cent formed part of the engine crew. At the time of the survey, respondents had been on board between less than a month and eighteen months $($ mean $=4.0, \mathrm{SD}=3.7)$.

Most of the survey respondents worked on container ships (21.5 per cent) or oil tankers (19.7 per cent), followed by bulk carriers (14.3 per cent). The majority of the vessels on which respondents worked were flagged in different European countries, including Sweden (12.8 per cent), Denmark (10.6 per cent), and Germany (8.0 per cent). About a third (32.2 per cent) of the respondents worked on vessels which are termed as Flags of Convenience registers (as defined by the ITF's fair practices committee ${ }^{6}$ ), including Liberia (7.0 per cent), Malta (6.6 per cent), Marshall Islands and Panama (5.1 per cent each).

\subsection{Overview of key variables included in the study}

The survey was designed to assess seafarers' perception of the effects of and the support received during the COVID-19 pandemic, as well as the impact on their mental health and wellbeing. An overview of the variables measured is presented in Figure 1.1.

\footnotetext{
${ }^{6}$ See https://www.itfglobal.org/en/sector/seafarers/flags-of-convenience, retrieved 14 September 2020.
} 


\section{Perceived effects of the pandemic}

- Effects on work/life on board

- Effects on workload

- Perceived safety (at sea / in port)

- Main difficulties \& challenges
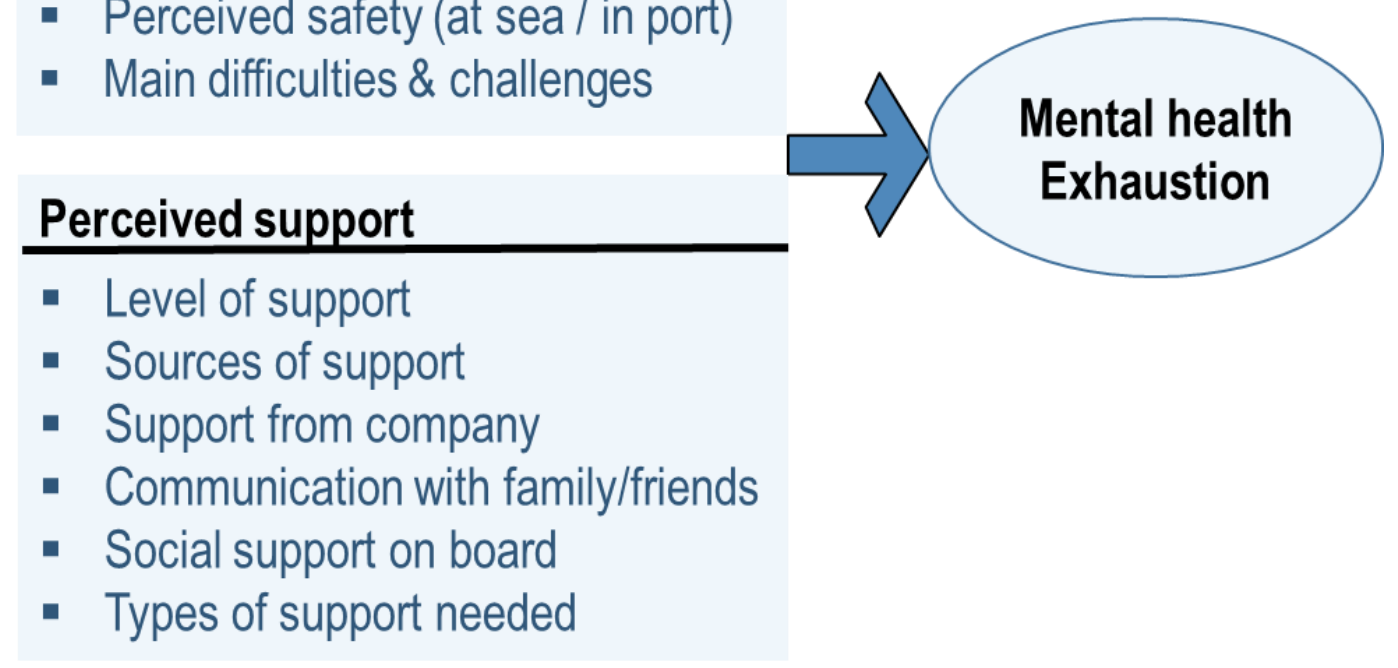

Figure 1.1. Overview of key variables included in the study.

\subsection{Limitations}

There are a number of limitations that need to be taken into consideration when interpreting the results of this study, such as the cross-sectional nature of the study. Moreover, most of the respondents (72.5 per cent) were officers, with almost half of the respondents engaged on Northern European flagged vessels. Further, data were collected through an online survey, hence the data are likely to include predominantly those who have access to the Internet. Therefore, in interpreting the findings of this study, it is important to note that the data are not based on a representative sample, and they might present a more positive situation than one might obtain from a more representative sample. 


\section{Perceived effects of the COVID-19 pandemic}

\subsection{Perceived effects of the pandemic on work/life on board}

Seafarers were asked how the COVID-19 pandemic affected different aspects of work and life on board, their family and their employment. Overall, the responses suggest serious impacts of the pandemic, with over 20 per cent of respondents reporting a very high or high impact in each of these areas. By far the most seriously affected area, according to survey responses, were crew changes, followed by ship-shore interactions (Figure 2.1).

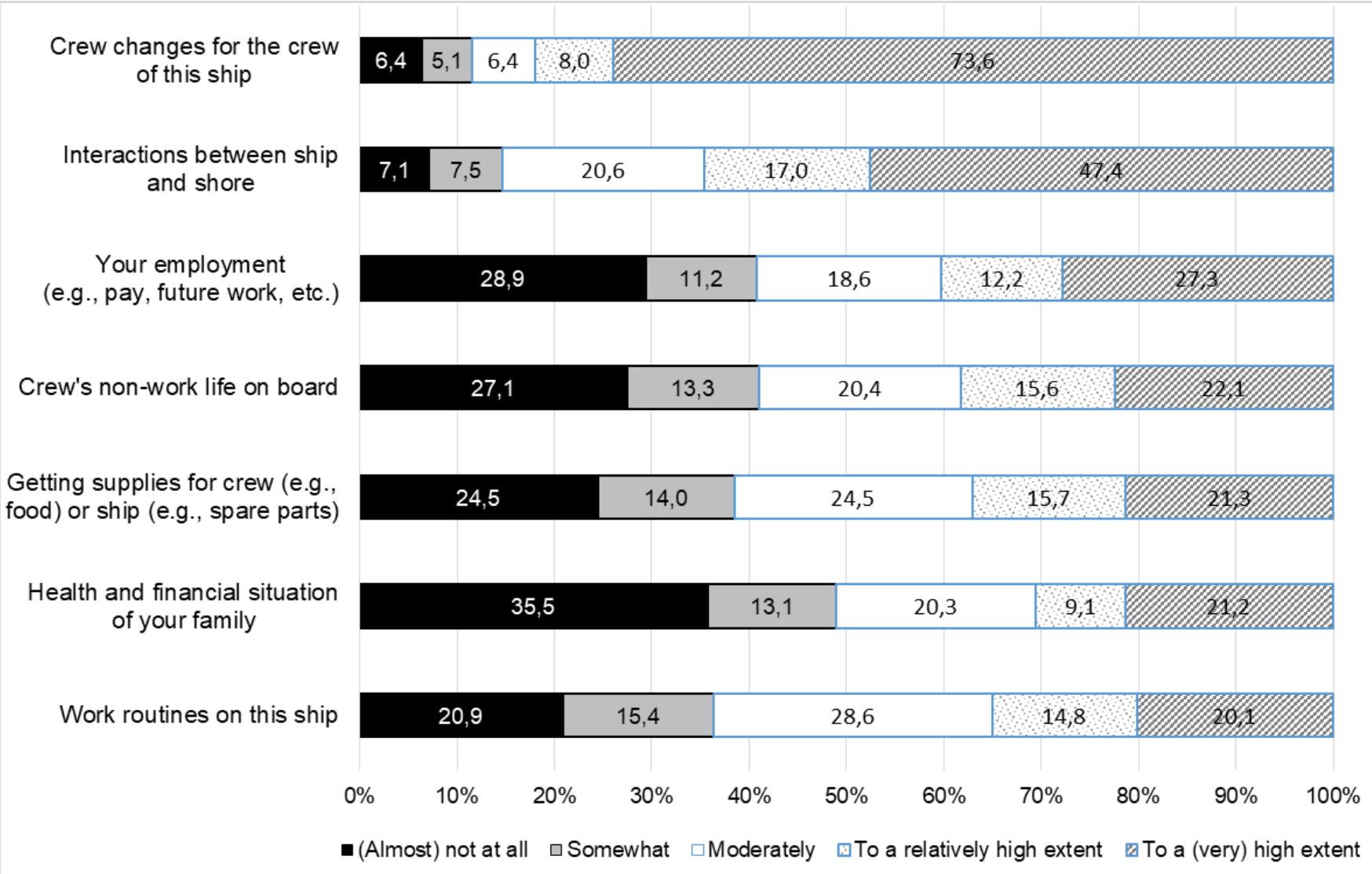

Figure 2.1. "How seriously has COVID-19 affected the following?" Numbers show the percentage of respondents who chose a particular answer category.

\subsection{Perceived effects on workload}

The survey also included questions on the current workload of respondents and the crew as a whole, compared to the workload before the pandemic. The findings include only the responses of seafarers who had been at sea prior to the start of the pandemic. Around half of the respondents reported an increase in their workload (47.8 per cent) and that of their crew (48.2 per cent). Around half reported that their workload had remained "about the same" (self: 46.6 per cent; crew: 44.7 per cent) since the start of the pandemic. A small group of respondents indicated that they experienced a decrease in their workload (5.2 per cent) or that of their crew (6.6 per cent). 


\subsection{Perceived effects on personal safety}

Although most of the respondents reported that they were not aware of anyone on board having been ill or infected with COVID-19, the risk of infection was a concern for many. Responses suggest that almost half of the respondents (42.2 per cent) did not feel safe during port calls (Figure 2.2). In contrast, 84.7 per cent agreed that they "felt safe while the ship was at sea".

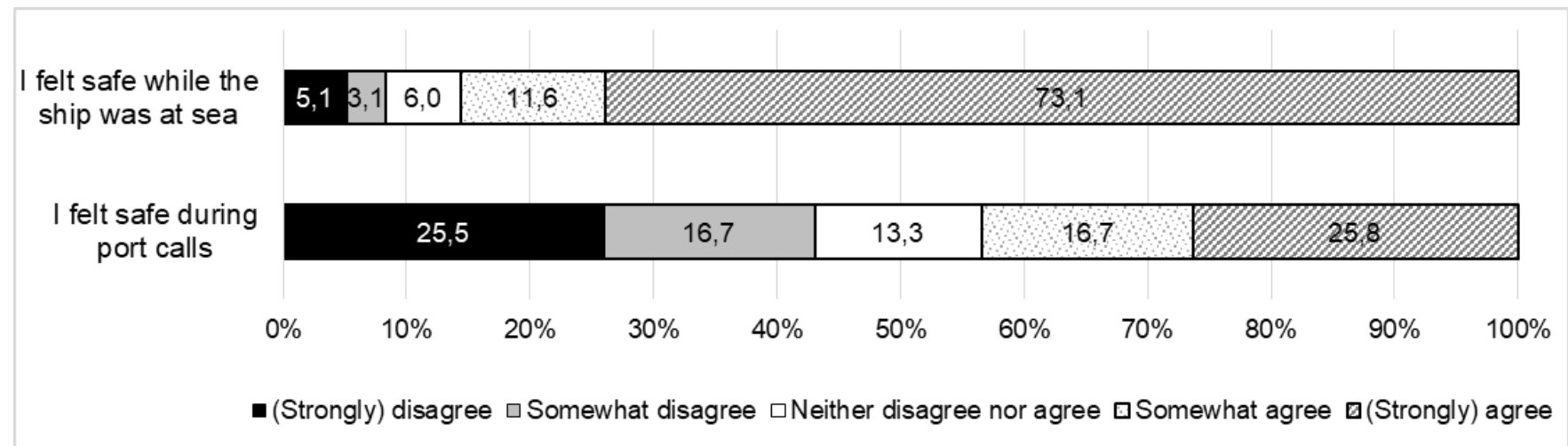

Figure 2.2. Feeling safe from COVID-19 when at sea and in port.

\subsection{Perceived difficulties and challenges}

To get a better understanding of the challenges faced by seafarers on board, respondents were asked to name the three main COVID-19 related difficulties or challenges they had faced in the last seven days. Figure 2.3 provides an overview of the types of challenges mentioned by respondents, grouped into broad categories.

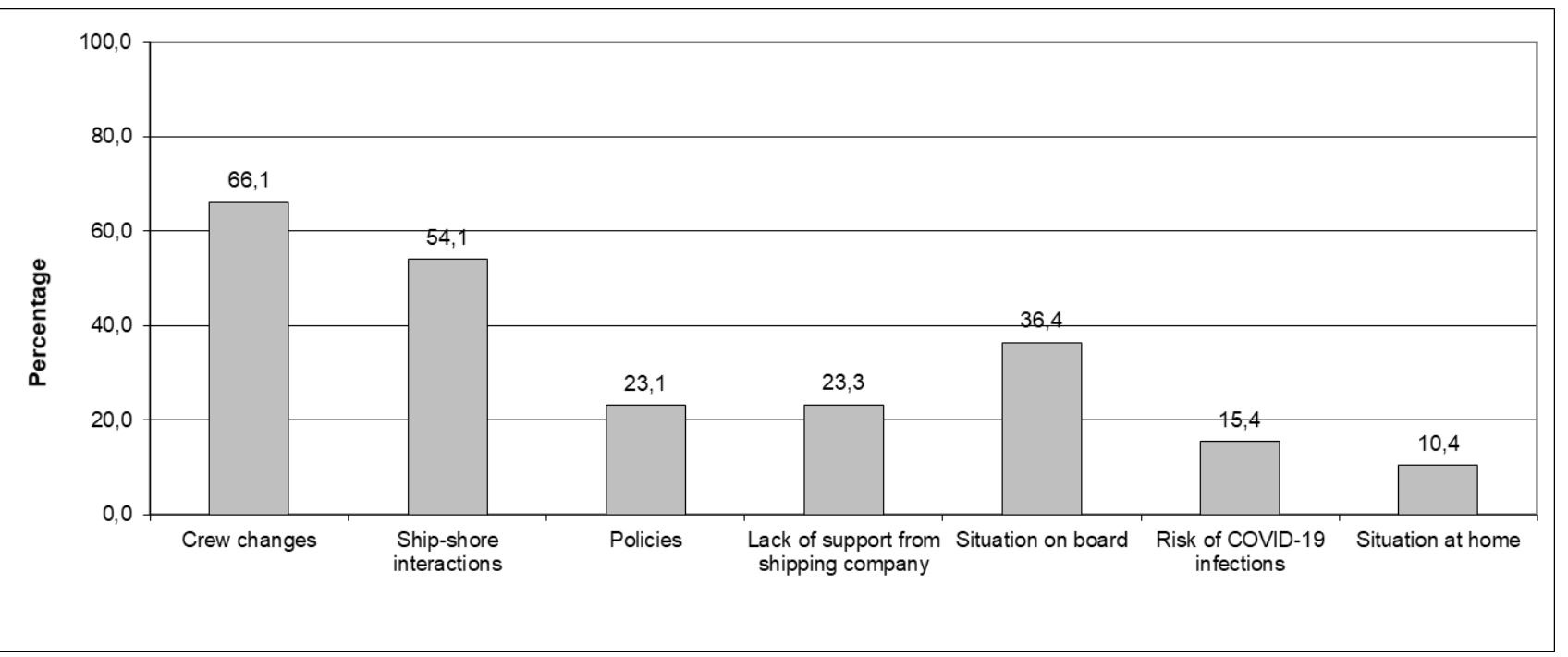

Figure 2.3. COVID-19 difficulties or challenges faced during the last seven days. Numbers show the percentage of respondents $(n=481)$ who mentioned a particular type of support in response to this open question.

Preliminary findings on each category include:

- Crew changes: Respondents highlighted limitations, cancellations, delays or difficulties with crew changes as a major challenge. Some responses were more detailed, noting for instance 
the uncertainty around crew changes (especially regarding crew change dates) and difficulties related to travelling to/from the ship due to visa restrictions, border closures, quarantine requirements, flight cancellations, diversity of rules (in some cases even within the same country), and changing rules.

- Ship-shore interactions: Over half of the respondents mentioned challenges related to shipshore interactions. This included not being able to go ashore (mentioned by 34.5 per cent), e.g. for medical care, for purchasing personal items and supplies (e.g., clothing, SIM cards, snacks) or for recreational purposes. Getting supplies was mentioned as a key challenge by 13.3 per cent; this included supplies for the ship (e.g. spare parts) as well as food.

- Policies: Challenges related to policies were mentioned by 23.1 per cent of respondents. Some statements specifically concerned policies in connection with crew changes (e.g., visa requirements, quarantine rules) while most related to port states' requirements and regulations as well as COVID-19 precautions taken by the crew during port calls. A frequently mentioned challenge was non-compliance with rules by others with whom crew members interacted. Others mentioned situations when policies were difficult or impossible to implement.

- Lack of support from the shipping company: Almost a quarter of the respondents (23.3 per cent) mentioned challenges concerning the perceived lack of support from the shipping company, such as lack of information, conflicting information, lack of communication, or high demands and pressure. Moreover, many respondents mentioned challenges related to expired or extended contracts (12.5 per cent) or challenges related to financial problems and job insecurity (7.1 per cent). Due to the difficulty of crew changes, some noted that their companies extended contracts instead of offering timely crew changes.

- Challenges concerning the situation on board were mentioned by 36.6 per cent. This included increased workloads (often due to additional tasks and paperwork in connection with COVID-19 regulations and requirements), fatigue due to high workload and extended contracts, and dealing with stress and negative emotions such as fear, anxiety, uncertainty, feeling locked-in on board, as well as tensions and aggression among the crew. Captains and senior officers also noted challenges with regard to passing on unpleasant news and explaining the situation to the crew.

- Risk of COVID-19 infections: For 15.4 per cent of respondents, a key challenge was the risk of COVID-19 infections. Many worried about being exposed to the virus. Most commonly, this was mentioned in relation to non-crew members that they might come in contact with during port calls, but also in connection with incoming crew members.

- Situation at home: Concerns about the situation at home were mentioned as a key challenge by 10.4 per cent. This included concerns about family matters, the health and/or the financial situation of their family, as well as the situation in their home country. Limited or difficult communication with friends and family at home were mentioned as well. For some, a key challenge was that Internet or other means of communication were expensive, slow or hardly available at all. 


\section{Level, sources and types of support}

The study aimed to also identify the level of support available to seafarers during the COVID-19 pandemic. Support may be available from different sources. This section considers support from individuals and organisations ashore (such as shipping companies, port state authorities, unions, and family and friends at home) as well as support from colleagues on board. The type of support can include information or practical guidance related to work, medical assistance, travel arrangements, as well as emotional support (i.e. someone to talk and listen).

\subsection{Perceived level of support and sources of support}

Responses suggested that there had been considerable variation in the level of support received by respondents and their fellow crew members since the start of the pandemic (Figure 3.1), indicating an almost 50/50 split between whether support was available or not.

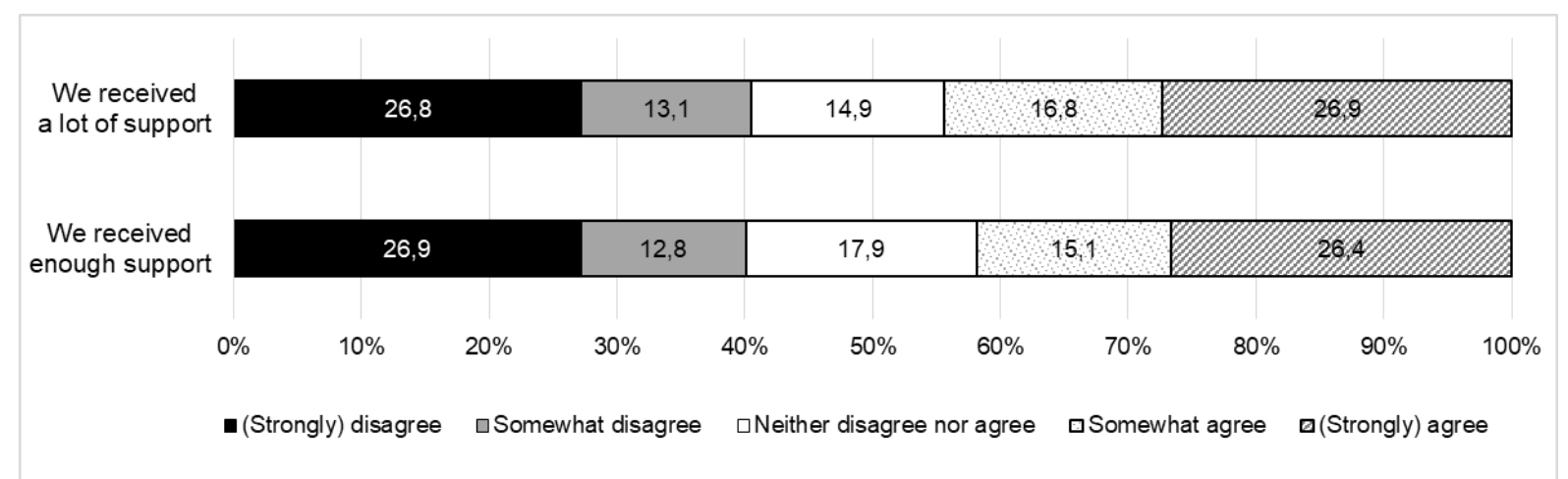

Figure 3.1. Perceived level of support since the start of the pandemic. Numbers show the percentage of respondents who chose a particular answer category for each question.

The survey also addressed the sources of support that respondents and their fellow crew members had received since the start of the pandemic (Figure 3.2). Respondents had the option to select more than one source of support. The shipping company (comprising ship owners, ship operators, crewing agencies, charterers or liner companies) was the most frequently selected category (68.1 per cent), followed by friends and family at home (62.3 per cent). Least frequently mentioned were port chaplains, seafarer centres and welfare organisations (8.0 per cent), and doctors, nurses or medical experts (9.5 per cent). 


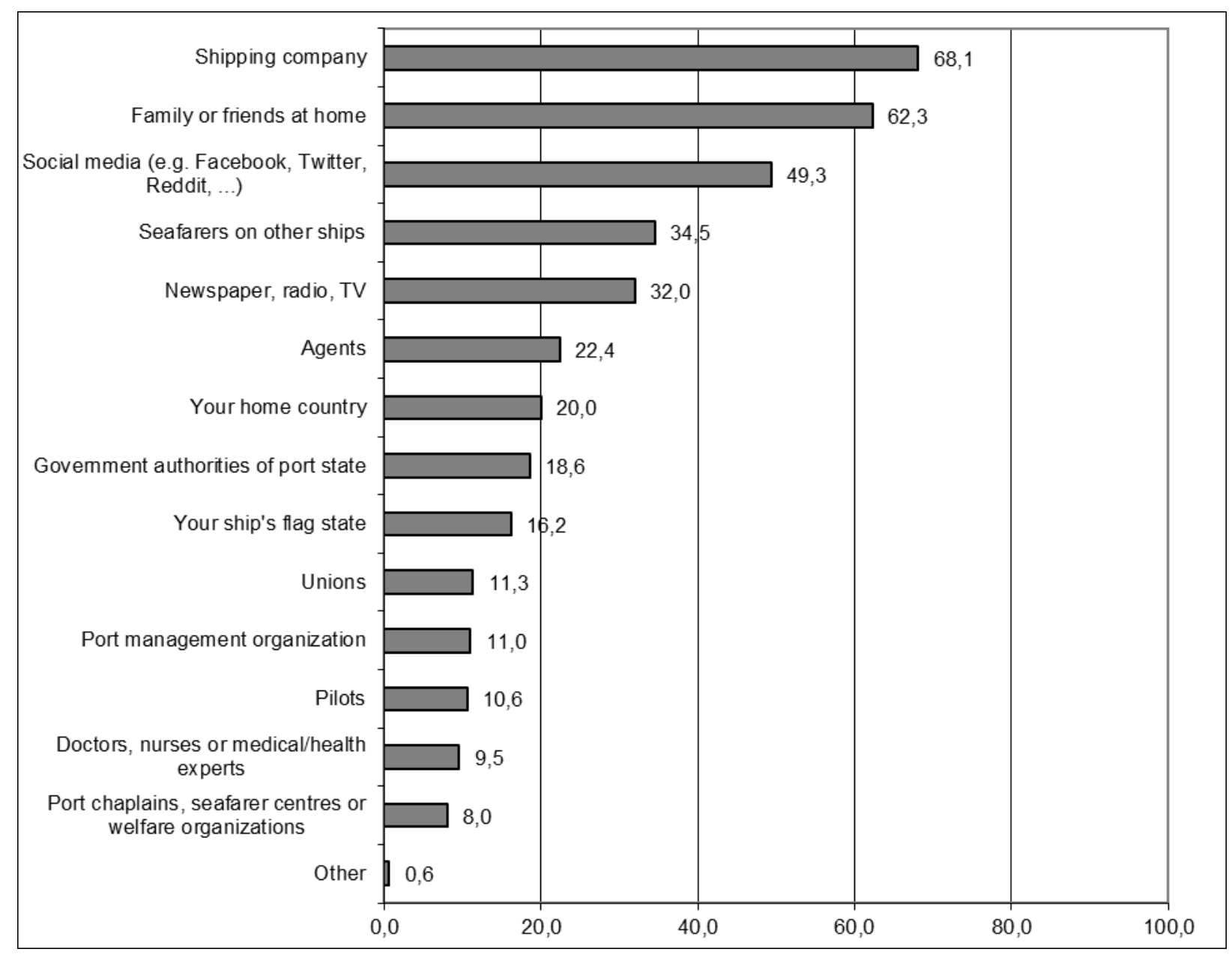

Figure 3.2. Main sources of support since the start of the pandemic. Numbers show the percentage of respondents who chose a particular answer category; respondents could select multiple categories if they wished.

\subsection{Support from the shipping company}

Respondents were asked to indicate the types of support they had received from their shipping company since the start of the pandemic. There was considerable variation between responses (Figure 3.3). The most frequently selected categories were medical advice and information on COVID-19 (85.7 per cent) and establishing COVID-19 onboard procedures (83.3 per cent). Least frequently mentioned was mental health support (31.1 per cent). Support in relation to crew changes was split 50/50, with only half of the respondents (51.1 per cent) reporting that they had received support from their companies.

Respondents were also asked about their experiences when contacting their shipping company (Figure 3.4). These questions were added to the survey at the end of July. 66.7 per cent of the respondents "strongly agreed" or "agreed" that they knew who to contact, while 7.7 per cent "strongly disagreed" or "disagreed" with the statement. Almost half (47.3 per cent) reported that they received the information or help they needed, whereas 19.1 per cent indicated that they did not. 42.8 per cent reported that they received a timely response, while 15.1 per cent indicated they did not. 


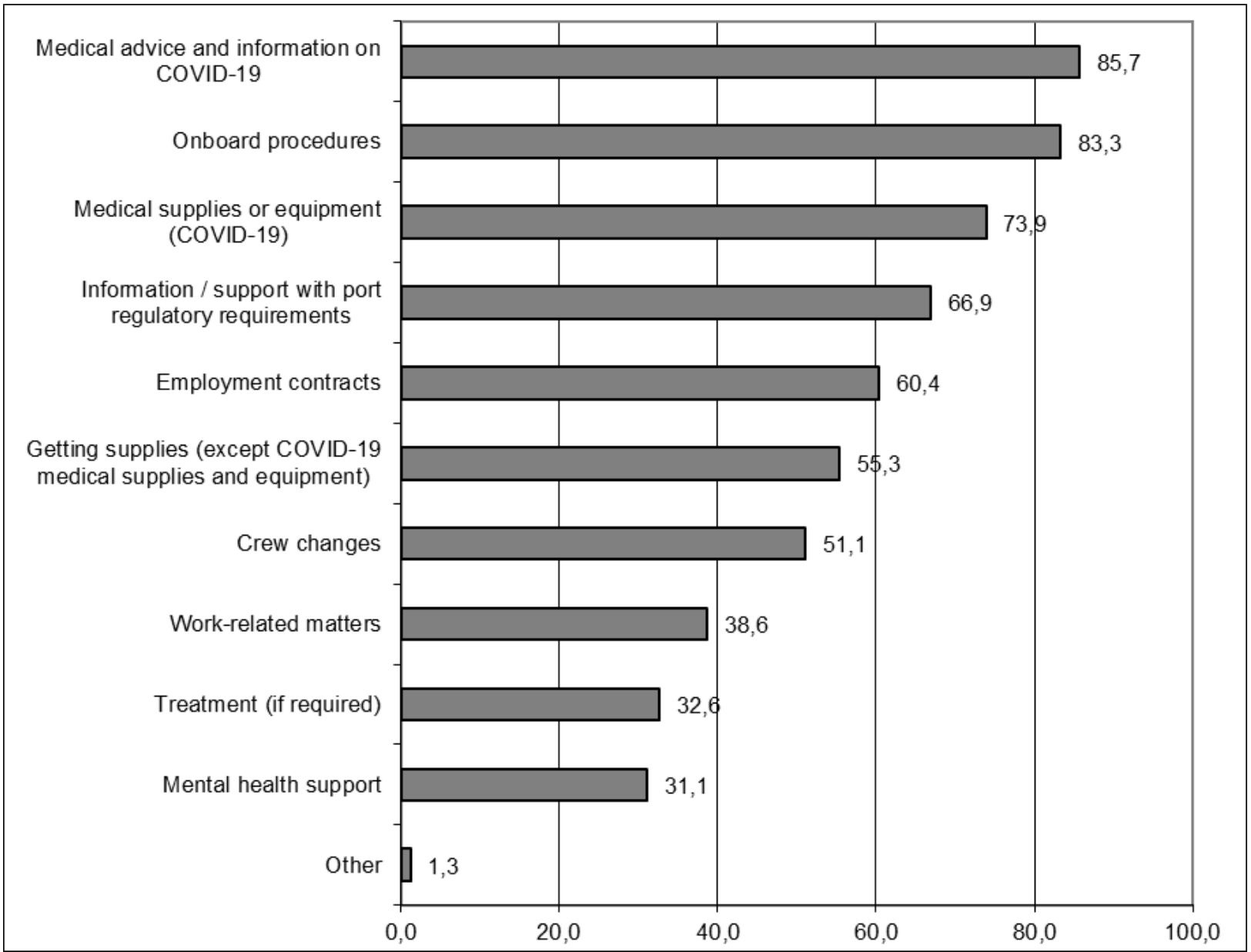

Figure 3.3. Types of support provided by the shipping company since the start of the pandemic. Numbers show the percentage of respondents who chose a particular answer category; respondents could select multiple categories if they wished.

I know the right person to contact.

I get the information or help that I need.

I get an answer within a short period of time.

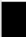

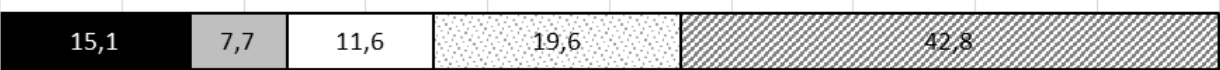

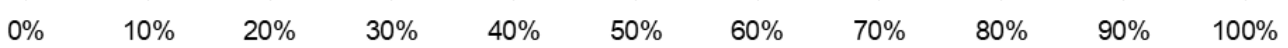

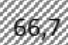

\begin{tabular}{|c|c|c|c|}
\hline 13,5 & 5,6 & 11,2 & 19,1 \\
\hline
\end{tabular}

Ш (Strongly) disagree $\square$ Somewhat disagree $\square$ Neither disagree nor agree $\square$ Agree somewhat $\square($ Strongly) agree

Figure 3.4. Respondents' contact with their shipping company. Numbers show the percentage of respondents who chose a particular answer category for each question. 


\subsection{Communication with family and friends at home}

The survey included questions on how frequently respondents communicated with family or friends at home in writing (e.g., via email, SMS or other text-based chat services) or by talking to them so that they could hear and/or see each other (e.g., telephone, WhatsApp, Skype). As shown in Figure 3.5, around 75 per cent of respondents reported that they communicated with friends and family at home once or several times per day in writing, and about half did so by talking.

35.5 per cent of the respondents reported having unlimited free Internet access on board, while about half (50.5 per cent) had limited free Internet access. 13.1 per cent had no free Internet access. Further, satisfaction with the speed and reliability of the Internet on board varied. While 16.9 per cent were "satisfied" or "very satisfied" with the speed and 20.7 per cent with the reliability of the Internet on board, 36.2 per cent were "very dissatisfied" or "dissatisfied" with the speed and 29.6 per cent with the reliability of the connection.

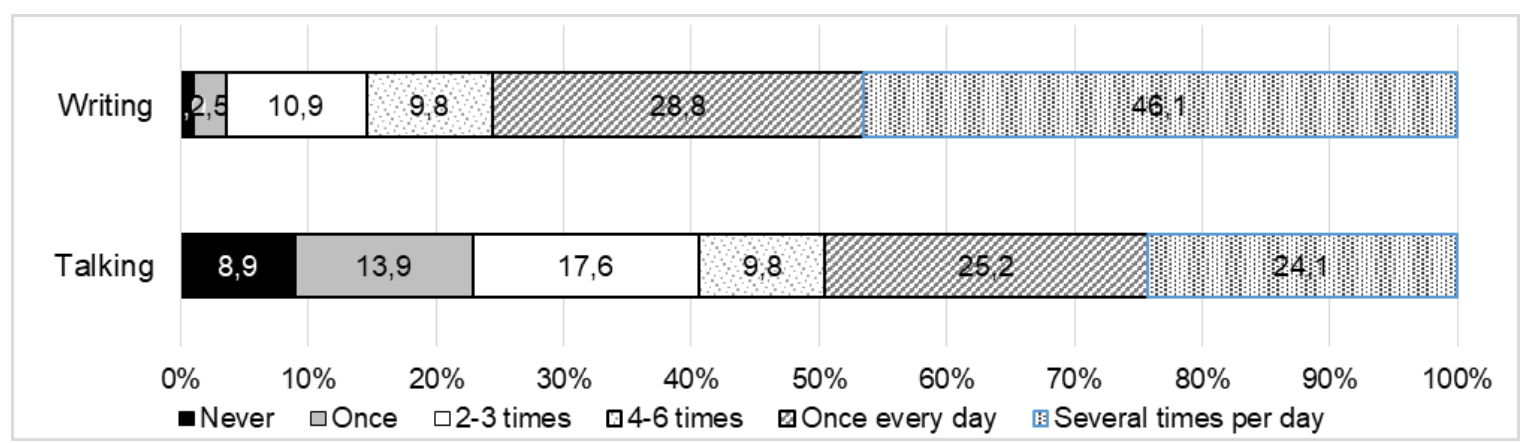

Figure 3.5. Frequency of communication with family or friends at home during the last seven days, in writing or by talking. Numbers show the percentage of respondents who chose a particular answer category for each way of communicating.

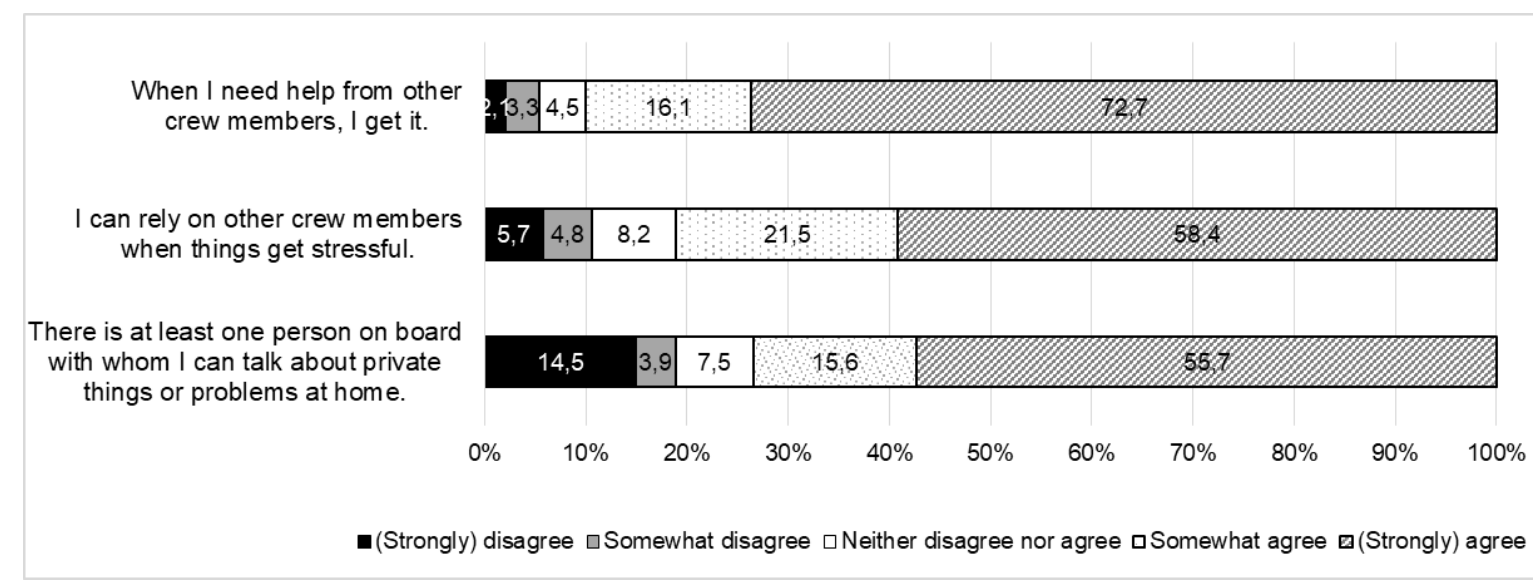

Figure 3.6. Perceived social support on this vessel. Numbers show the percentage of respondents who chose a particular answer category for each question.

\subsection{Perceived social support from fellow crew members}

While crews might receive support from individuals and organisations ashore, practical support (e.g. help with work tasks) and emotional support (e.g. someone listening) from fellow crew members can be important as well. In the survey, respondents were asked to what extent they thought that support from other crew members would be available to them (Figure 3.6). Most of the respondents (72.7 
per cent) "strongly agreed" or "agreed" that they would be able to get help from other crew members if needed, and 58.4 per cent reported that they could rely on their colleagues even in stressful situations. The percentage was lower with regard to emotional support; 55.7 per cent were confident that there was someone on board who they could talk to about private matters or problems at home, whereas 18.4 per cent disagreed with the statement (somewhat disagree: 3.9 per cent; disagree: 8.5 per cent; strongly disagree: 6.0 per cent).

\subsection{Perceived type of support needed}

To get a better understanding of the support needed by seafarers, the survey included an open question asking seafarers what they or their fellow crew members would like more support with. A few respondents (2.2 per cent) stated that they needed no further support, while 299 respondents (44.6 per cent) mentioned between one and five things that they would like more support with.

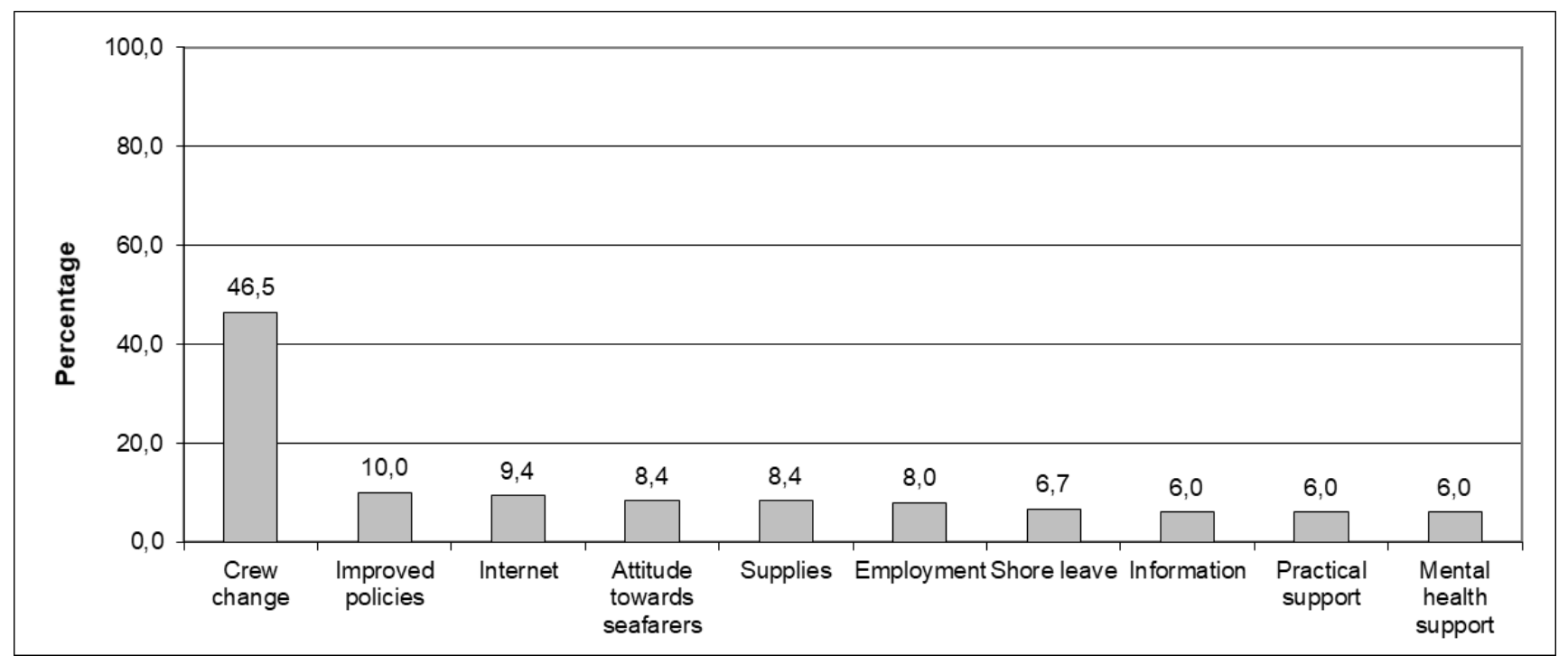

Figure 3.7. "What would you or fellow crew members like more support with?" Numbers show the percentage of respondents $(n=299)$ who mentioned a particular type of support in response to this open question.

Examples of required support as expressed by respondents include the following:

- Organisation of crew changes, irrespective of crew members' nationalities.

- Establishment of best practices and clear, simple and consistent rules.

- Provision of better Internet and communication for maintaining contact with family and friends at home, as well as for keeping informed, and for entertainment and recreation on board.

- Change of negative attitudes towards seafarers (being treated "as dangerous" or "like trash" by local governments) and recognition of seafarers' contribution as key workers.

- Support with getting supplies, including PPE, medicine, and personal supplies.

- Shore leave for doctors' visits, purchasing personal items (e.g., clothing) or recreation.

- Financial security and job security.

- More support and more transparent information from the company.

- Support for onboard life and activities, such as medical service access, welfare and recreation for the crew.

- Mental health support for crew members and for family at home. 


\section{Mental health and exhaustion}

\subsection{Mental health}

The survey included five questions on mental health, asking respondents to indicate how often they had experienced each of the five symptoms during the last seven days (Figure 4.1). The responses show that 41.5 per cent of respondents indicated "feeling sad, depressed or hopeless" several times, almost every day or every day in the last seven days. More than half ( 52.5 per cent and 56.9 per cent) indicated "feeling afraid, anxious or worried" and "always worrying about something", respectively, several times, almost every day or every day during the last seven days.

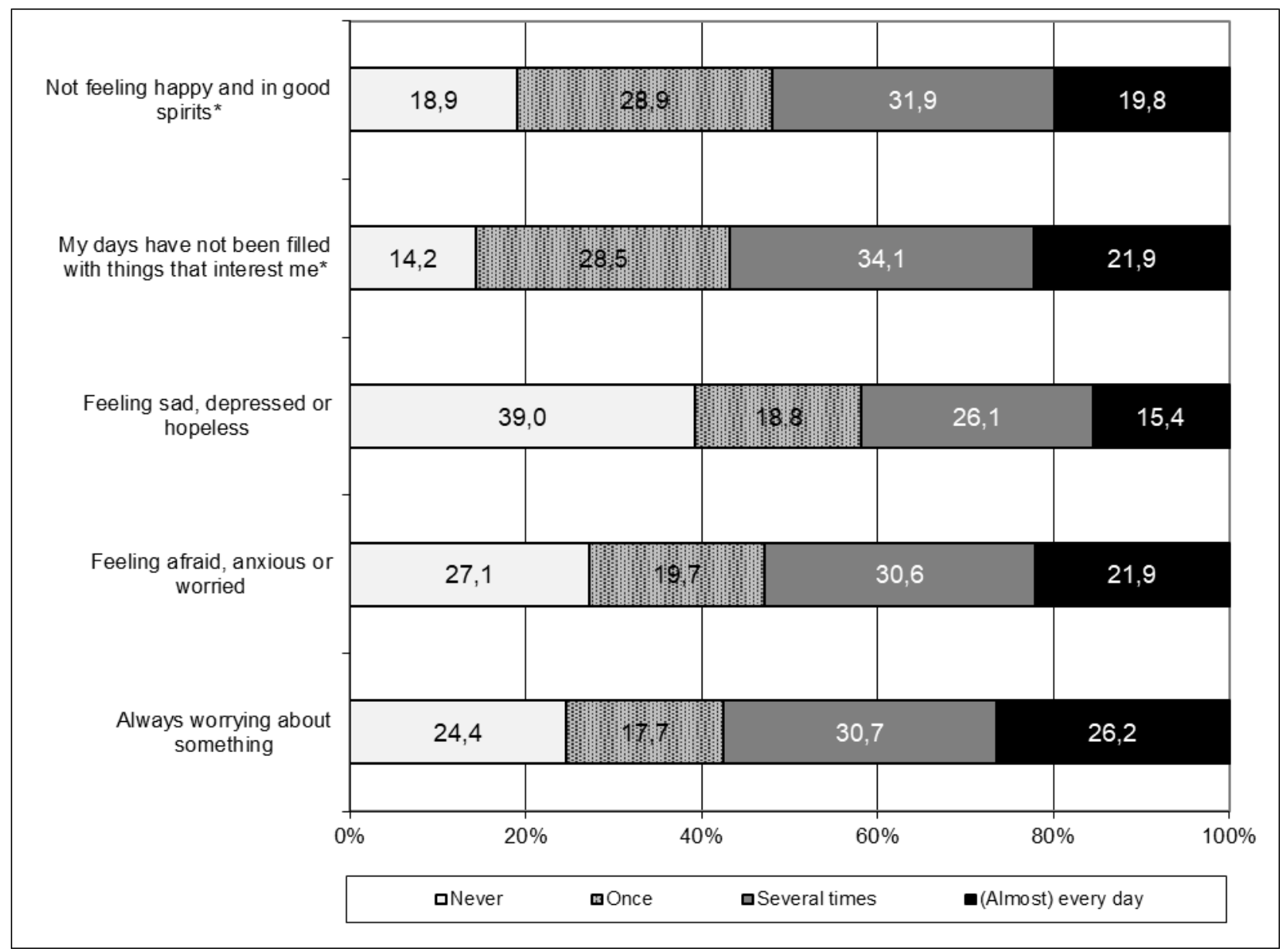

Figure 4.1. Mental health during the last seven days. Numbers show the percentage of respondents who chose a particular answer category in response to a particular question. *This question was worded positively in the survey and was reverse-coded for the report.

\subsection{Exhaustion}

The survey also included six questions about symptoms of exhaustion experienced by seafarers during the last seven days (Figure 4.2). On average, respondents had experienced each of these between "once" and several times" within the last week. But answers varied considerably. On the one hand, 7.2 per cent reported that they had "never" experienced any of these during the last seven days. On the other hand, 11.9 per cent had experienced all of them on average "almost every day" or "every day". Feeling exhausted, feeling tired and sleeping problems were most common. About a 
third of the respondents had experienced them "several times" during the last seven days, and 20 per cent had experienced them "almost every day" or "every day".

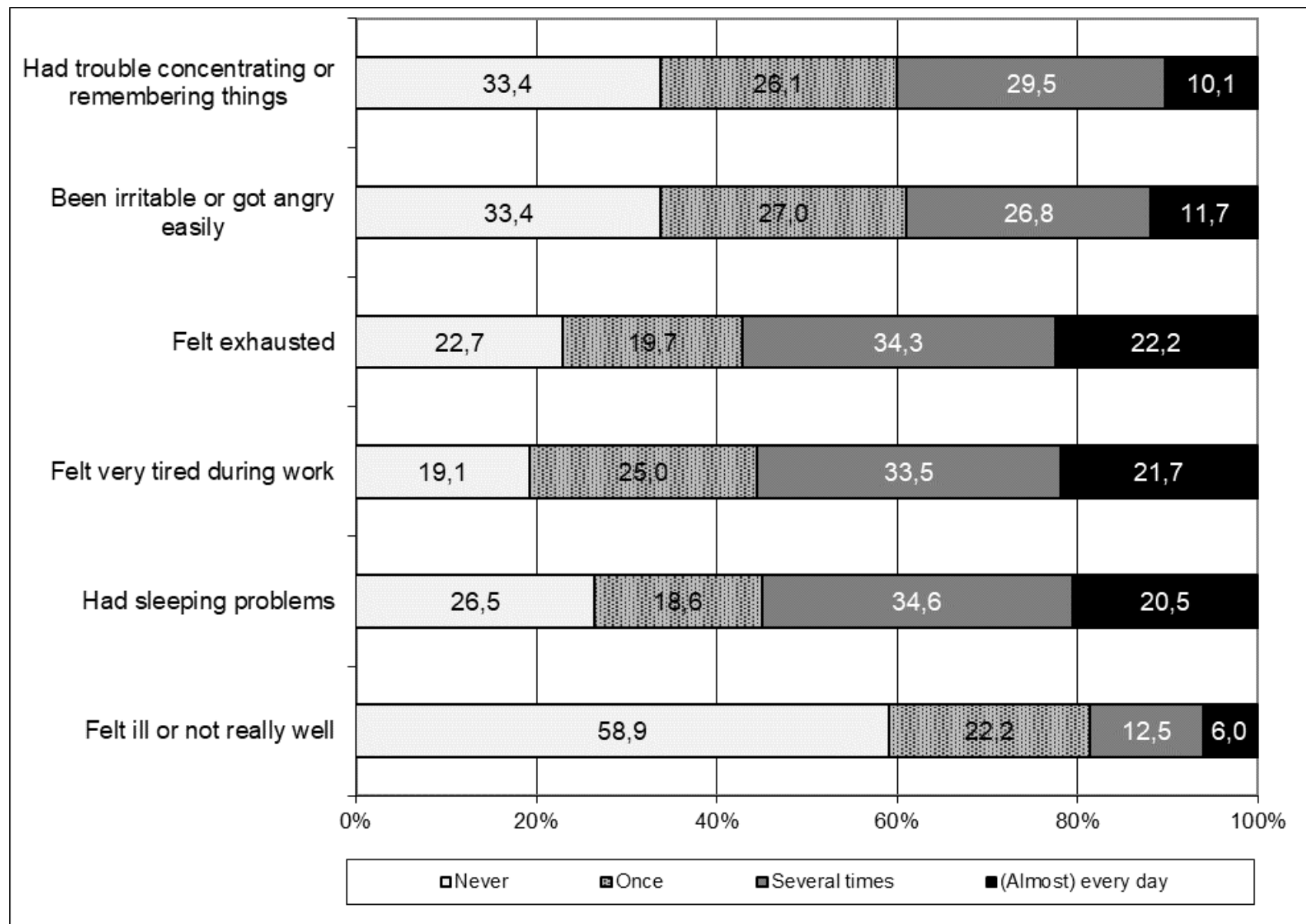

Figure 4.2. Exhaustion during the last seven days. Numbers show the percentage of respondents who chose a particular answer category in response to a particular question. 


\section{Conclusions and recommendations}

This report provides an overview of preliminary findings of a study on the experiences of seafarers during the COVID-19 pandemic, as well as on the effects of the COVID-19 pandemic on seafarers' mental health and the level of support they received. The findings suggest that the pandemic has further exposed and amplified problems and vulnerabilities that had already been noted in earlier, pre-pandemic studies on the health, welfare and safety of seafarers. ${ }^{7}$

The effects of the pandemic, as understood from the perspective of the seafarers in this study, reveal a number of shortfalls and challenges experienced by seafarers onboard international commercial vessels. In particular, responses to several questions (i.e. questions on the effects of the pandemic, main challenges and need for more support) highlighted crew changes as a key challenge. In their comments, respondents referred to cancellations of crew changes, uncertainty (especially around crew change dates) as well as difficulties related to the journey to/from the ship due to, among other things, flight cancellations, border closures, and visa and quarantine requirements. Cancellations and delays of crew changes led to extended time (in some cases up to 18 months) on board.

Other challenges included ship-shore interactions, getting supplies, the social and work situation on board, challenges related to employment (pay, contracts, job insecurity) as well as concerns about the health and financial situation of seafarers' families at home. In addition, around half of the respondents experienced an increase in workload when compared to the workload prior to the pandemic.

Respondents also identified the lack of clear and consistent policies and procedures, and the lack of a shared understanding of best practices as a challenge, both in relation to national policies that affected crew changes, and in relation to COVID-19 precautionary measures during port calls. Seafarers also perceived a lack of compliance with COVID-19 precautions (e.g., using PPE, observing social distancing rules) by port personnel and others with whom they were required to interact, and were concerned about being exposed to infections. Perhaps reflecting such concerns, less than half of the respondents reported that they felt safe during port calls.

Moreover, respondents indicated that COVID-19 precautionary measures enacted by national and local government authorities and/or ports restricted crews' access to shore, both for recreation, making necessary personal purchases, and for medical care. In their comments, the lack of shore leave was highlighted as a major concern by many respondents, and sometimes linked explicitly with mental health and tensions on board.

The findings indicate challenges related to mental health, with about half of the seafarers reporting symptoms of depression and/or anxiety several times, almost every day or every day during the last week. In addition, seafarers' comments suggested that the strain of being "locked up" on board for such a long time, often without the possibility of shore leave, could contribute to heightened levels of tensions and conflicts among the crew.

Long periods of time spent on board, together with an increase in workload for many of the respondents, was also reflected in heightened levels of exhaustion, with over half of the respondents indicating that they felt exhausted and tired during work several times, almost every day or every day during the last week. High levels of exhaustion are concerning because they can increase the

\footnotetext{
${ }^{7}$ See for instance Andrei, D., Grech, M, Ho, J., Mcllroy, T., Crous, R., Griffin, M., Neal, A. (2018) Assessing the determinants of safety culture in the maritime industry. Report LP130100215;
} 
risk of injuries and accidents. ${ }^{8}$ With sustained high levels of exhaustion, there is also a risk of chronic fatigue build up, with negative consequences for seafarers' physical and mental health. ${ }^{9}$

Support from individuals and organisations ashore, as well as support from fellow crew members on board, can be vital to mitigate the negative effects of the pandemic, as well as mental health problems and fatigue. ${ }^{10}$ In this survey around 40 per cent of respondents indicated that the level of support needed was not provided. Responses suggest that the main sources of support were the shipping company, as well as friends and family at home and social media, whereas only 16-20 per cent reported receiving support from government authorities of their home countries, flag states and/or authorities of the port states where they called. Moreover, almost half reported that they had not received support with crew changes from their company, and only 31.1 per cent had received mental health support, making this the least frequently mentioned type of support from shipping companies. In response to an open-ended question, 46.5 per cent of respondents identified crew changes as the area in which they needed more support, followed by improved policies (10.0 per cent) and access to Internet (9.4 per cent).

\section{Recommendations}

The findings draw attention to several areas of support which different maritime stakeholders can offer to seafarers during the COVID-19 pandemic. The provisions set out in the MLC, 2006 provide the foundation to ensure seafarers are afforded decent working and living conditions on ships and to ensure a comprehensive worldwide protection of the rights of seafarers. Moreover, the MLC, 2006 requires member states to cooperate with one another for the purpose of ensuring the effective implementation and enforcement of the Convention. This provision is significant in the context of a global pandemic, with implications for the organisation of crew changes and the provision of other forms of assistance. It will be critical for shipping companies and governments to take a leadership role in ensuring that MLC, 2006 provisions continue to be upheld and that seafarers are afforded the support needed.

Recommendations for shipping companies include the following:

- Ensure that the right of every seafarer to a safe and secure workplace is upheld, including the implementation of effective protective measures and the provision of medical care.

8 See for instance Rosa, R. R. (2012). Long work hours, fatigue, safety, and health, in The handbook of operator fatigue, Matthews, G., Desmond, P. A., Neubauer, C., and Hancock, P. A., Editors. Ashgate Publishing Ltd.: Surrey;

Williamson, A., D. A. Lombardi, S. Folkard, J. Stutts, T. K. Courtney, and J. L. Connor (2011). The Link between Fatigue and Safety. Accident Analysis \& Prevention, 43: 498-515. doi: 10.1016/j.aap.2009.11.011

${ }^{9}$ Caruso, C. C., Bushnell, T., Eggerth, D., Heitmann, A., Kojola, B., Newman, K., Rosa, R. R., Sauter, S. L., and Vila, B., (2006). Long Working Hours, Safety, and Health: Toward a National Research Agenda. American Journal of Industrial Medicine, 49: 930-942; Johnson, J. V. and Lipscomb, J., (2006). Long Working Hours, Occupational Health and the Changing Nature of Work Organization. American Journal of Industrial Medicine, 49: 921-929; Härmä, M., (2006). Workhours in relation to work stress, recovery and health. Scandinavian Journal of Work and Environmental Health, 32: 502-514, doi: 10.5271/sjweh.1055

10 Nahrgang, J. D., Morgeson, F. P., Hofmann, D. A. (2011). Safety at work: a meta-analytic investigation of the link between job demands, job resources, burnout, engagement, and safety outcomes. Journal of Applied Psychology, 93(1), 71- 94; Wadsworth, E.J.K., P.H. Allen, R.L. McNamara, and A.P. Smith. (2008). Fatigue and Health in a Seafaring Population. Occupational Medicine, 58: 198-204. doi:10.1093/occmed/kqn008. 
- Ensure that viable repatriation plans are in place for timely crew changes that account for all eventualities.

- Provide transparent and up-to-date information about crew changes, international and national policies and regulations in ports of call, as well as up-to-date medical information on effective COVID-19 prevention and treatment.

- Provide free, fast and reliable Internet on board for seafarers' personal use.

- Ensure that seafarers have access to essential supplies and support, including medical care and essential goods, as well as possibilities for shore leave.

- Ensure that mental health support is available to all crew members at all times, and provide training on mental health awareness and first aid to all seafarers.

- Ensure a holistic approach to managing and reducing the risk of fatigue at sea by implementing a fatigue risk management system as per the International Maritime Organization (IMO) Guidelines on Fatigue ${ }^{11}$. This is even more critical amid the COVID-19 pandemic with seafarers spending more time at sea.

- Continue cooperation with seafarer representatives such as unions and welfare organisations to monitor seafarers' well-being and take appropriate action as necessary.

Governments should work together to:

- Recognise seafarers as key workers to facilitate crew changes, allow shore leave and provide access to shore-based services.

- Raise public awareness of seafarers as key workers to remove prejudice and negative attitudes towards seafarers.

- Continue consultation and co-operation between seafarer representatives, shipping companies and governments (flag states, port states and seafarers' home countries). Under exceptional circumstances, consideration for exempting aspects of the MLC, 2006 provisions should include consultation with seafarers or their representatives to ensure all safe options are considered.

- Ensure vessels' continued compliance with international laws and regulations, such as the MLC, 2006 and SOLAS;

- Monitor the well-being of seafarers coming into their jurisdiction and ensure that as per the MLC, 2006 seafarers' complaints are investigated.

\footnotetext{
11 International Maritime Organization, Guidelines on Fatigue MSC.1/Circ. 1598
} 